\title{
Redistributed manufacturing system under uncertain evaluation using multi criteria decision making
}

\author{
Ponugupati Narendra Mohan*a ${ }^{\text {, Prof. Chalamalasetti Srinivasa Rao }}$ \\ ${ }^{\mathbf{a}, \mathbf{b}}$ Dept. of Mechanical Engineering, Andhra University, A.P, India \\ ${ }^{*}$ narendramohan.p@ gmail.com
}

Article History: Received: 10 November 2020; Revised 12 January 2021 Accepted: 27 January 2021; Published online: 5 April 2021

\begin{abstract}
Man In recent day's occurrence of a global crisis in Environmental (Emission of pollutants) and in Health (Pandemic COVID-19) created a recession in all sectors. The innovations in technology lead to heavy competition in global market forcing to develop new variants especially in the automobile sector. This creates more turbulence in demand at the production of new models, maintenance of existing models that are obsolete while implementation of Bharat Standard automobile regulatory authority BS-VI of India. In this research work developed a novel model of value analysis is integrated by multi-objective function with multi-criteria decision-making analysis by incorporating the big data analytics with green supply chain management to bridge the gap in demand to an Indian manufacturing sector using a firm-level data set using matrix chain multiplication dynamic programming algorithm and the computational results illustrates that the algorithm proposed is effective.
\end{abstract}

Keywords: Mathematical Modelling; Manufacturing System; Uncertainty; Big data analytics; Green supply chain management

\section{Introduction}

The majority of large companies and an important number of small and medium-sized enterprises have been incorporating policies and actions aimed at improving their sustainability. The technical issues related to sustainability of green supply chain management system (GSCMS) are the generation, processing, and analysis of data that will allow greater effectiveness and efficiency in business processes, as well as performance control and support for supply chain decision-making. This is where the concept of Industry 4.0 and the use of Big Data technology come into play. It allows products, machines, components, individuals, and systems to create a smart network so that it can integrate cyber-physical systems to act quickly by linking information and physical memory to the smart network for faster and more effective service environments [1] and the contribution of Industry 4.0 to more sustainable industrial value creation will be remarkable in the future [2].The architecture of a cellular manufacturing system (CMS) is the formation of similar families of parts and the grouping of machines into manufacturing cells as machine-made parts. Naturally, each part can be made by a single production cell with a simplified flow of material to divide the complex manufacturing process flow into optimal subgroups describes the flow of processes to develop effective CMS [3] and the productivity of the supply chain (SC) established a distributed relationships and connections between the stages of production, manufacture, and distribution of the raw materials [4,5]. Similar parts types are grouped to use the machinery and general-purpose machines set up to manufacture new models with a variety of demand in less cost and time by CMS gives the greater versatility, and a range of products are produced through transformation of workshops are benefitting by i) space reduction ii) fewer machines and iii) smaller distance moving pieces and smaller setup times for machines are required [6,7]. A conventional CMS does not enforce any product's variations in demand over multiple periods produce inefficient cells from one cycle to the next cycle. Thus dynamic cellular manufacturing system (DCMS) implemented to reduce the disadvantages of classical CMS by rearranging the part-families and machine groups [8]. In a modern manufacturing process the decision-making in the event of internal disruptions is a major challenge to a new multi-commodity flow-based network design for the multi-period cell formation issue to reduce the overall manufacturing cost(s)uses the Prometheus methodology (PM) to a dynamic multi-agent scheduling framework to manufacturing flow lines (MFLs) by considering the various customer specifications[9,10].A novel approach for the classification of goods based on the level of sophistication of assembly systems are used to define the degree of complexity of selection of individual components for reconfigurable manufacturing systems (RMS) is perceived as the realm of manufacturing due to its evolving[11] and versatile existence[12,13]. 


\section{Literature Review}

The cost of cell rearrangement in a cellular design must be as small as possible over a period of system design as the time spans are further broken down into smaller ones. In the first step, a bottom-up aggregation technique is proposed to mitigate the "normalized inter-class flow" and in the second level, a validation procedure of machine to cell further enhances the cell formation in long-term improvements to demand [14,15]. Song [16] introduced a novel way of implementing cell layout and managing output over several periods using a technique to build versatile manufacturing cells with dynamic demand changing the production volume and duration of cluster layout for each component are calculated in this model to layout the cells with dynamic demand[17]. A scheduling approach as cost reduction, reallocation and lowering the cost of machinery with a constraint of space efficiency as classical CMS was inferior when compared with DCMS based on system parameters with usage and throughput time along with the work-in-process criteria proposed for allocating operations on various machines and operation-parts to specified machines and the cells were established for production and to produce a better design $[18,19]$.

Wilhelm[20] addressed the problem of reconfiguration of machine cells along with the component family pattern for many times as the goals are cell size restriction, the limited capacity of the machines and numerous "copies" of a machine type was over the planning horizon to optimise the cost of in-between cell movements through an integer programming for multi time intervals decomposed into sub-problems to generate solutions in faster way [21] and Taboun [22] observed variations in demand over the long term when developing cell(s) leads to the optimization of the trade-offs between the cost of cell reallocation, the purchasing of equipment, the leasing of parts to different cells and the investment of the capital. Wicks [23] introduced multi-period cell formation using an integer model analysis of reducing inter-cell movement by minimizing the replication of equipment needs to be minimized the cell formation with multiple objectives as demand variations by type of component were defined and compared with the cell formation[24]. A dual-stage process with dynamic programming under circumstances of differing product demand as a widespread system allocation problem in curbing handling costs with an integral linear programming by generalized multi-criteria[25], the risk of rearranging equipment must be minimized, managing product returns was deemed necessary in the production plan, remanufacturing control, and inventory control of product return(s) and downside risks in the volume and existence of the returned goods extracted for re-manufacture may have a significant effect on the gain generated from remanufactured goods[26,27].

A similarity coefficient across a variety of routes to build cells for fabrication with machine failures and demand fluctuation in multiple cycles including the allocation of dynamic cells with dividing lots, cell size limits, a sequence of operations, various routings, lot, system adjacency constraints[28,29] and are effectively solved a PMMC-SA (Parallel Multiple Markov Chain- Simulated Annealing) algorithm[30]. Schaller [31] model identifies cells with a fixed machine(s) are created to multi functional services to improve versatility in scheduling, machine types are created for particular duration to fulfil CMS is the fact that this type of system of the same cluster is not automatically brought into physical proximity in virtual CMS[32,33]. The robust design strategy to fixed cells will be inefficient in any given time defined as a drawback of strategies are overcome in collaborative robotic cells for assembly or production using a bi-objective evolutionary cell scheduling problem (CSP) under the time of use (TOU) are built with the following objectives i) total cost of the production system, ii) gross delayed time jobs $[34,35]$. The growth in the creation of distributed production systems requires greater efficient technologies to facilitate networked management of resources such as the manufacturing automation protocol (MAP) explicitly designed to manage networked manufacturing devices [36]. This paper will address a strategy for solving the reconfigurable cell formation problem in the sense of a complex production environment that integrates various production parameters with a non-linear programming model to develop will be defined in the section below.

\section{Mathematical model formulation:}

A nonlinear mixed-integer mathematical model based on a live case study of cell formation in a complex environment with a multi-criteria decision model blends many parameters including a product mix of complexity and variety, a variance of product demand, variations in batch size, the order of operation, alternative routings, duplicate machines, time of processing are to obtain optimal manufacturing cost(s) over several periods.

\subsection{Notations used are}

The indices are

$\begin{array}{ll}\mathrm{s} & \text { Manufacturing cells }(\mathrm{s}=1, \ldots, \mathrm{S}) \\ \mathrm{n} & \text { Types of machines }(\mathrm{n}=1, \ldots, \mathrm{N}) \\ \mathrm{t} & \text { Types of parts }(\mathrm{t}=1, \ldots, \mathrm{T})\end{array}$


j Part $\mathrm{n}$ operations required $(\mathrm{j}=1, \ldots, \mathrm{Ot})$

h Periods of time $(\mathrm{h}=1 \ldots, \mathrm{H})$

The input parameters are

$\mathrm{T} \quad$ Number of different types of parts

$\mathrm{O}_{\mathrm{t}} \quad$ Number of operations by type of part ' $\mathrm{t}$ '

$\mathrm{N} \quad$ The number of different types of machines

S Total number of cells able to be produced

$\mathrm{H} \quad$ Number of periods

$\mathrm{D}_{\text {th }} \quad$ Type ' $\mathrm{n}$ ' part requirement in time period ' $h$ '

$t_{j t n} \quad$ The processing time needed for processing part ' $t$ ' operation ' $j$ ' on machine type ' $n$ '

$a_{\mathrm{jtn}} \quad=1$, where part type ' $\mathrm{t}$ ' operation ' $\mathrm{j}$ ' can be performed on machine type ' $n$ '; $=0$, otherwise.

$B_{t}^{\text {Intra }} \quad$ The batch size for part type ' $t$ ' intracell movements

$\mathrm{B}_{\mathrm{t}}^{\text {Inter }} \quad$ The batch size for part type ' $\mathrm{t}$ ' intercell movements

$I_{t}^{\text {inter }} \quad$ Intercell handling of the material costs per unit

$I_{t}^{\text {Intra }} \quad$ Intracell handling of the material costs per unit.

$\alpha_{\mathrm{n}} \quad$ The amortized type ' $\mathrm{n}$ ' machine cost per time period.

$\beta_{n} \quad$ Machine type ' $n$ ' operating cost per unit time.

In this function, per cycle a unit of time minutes.

$\delta_{\mathrm{n}} \quad$ Relocation costs for type 'm' system including deployment, move, and uninstallation

$\mathrm{T}_{\mathrm{n}} \quad$ Time-capacity of machine ' $\mathrm{n}$ ' for each cycle in terms of unit time (minutes).

The decision variables are

$\begin{array}{ll}\mathrm{N}_{\mathrm{nsh}} & \text { Number of ' } \mathrm{n} \text { ' model machine in period ' } h \text { ' allocated to cell 's' } \\ \mathrm{K}_{\mathrm{nsh}}{ }^{+} & \text {Number of machine type model ' } \mathrm{n} \text { ' added in period 'h' to cell 's' } \\ \mathrm{K}_{\mathrm{nsh}}{ }^{-} & \text {Machine model number ' } \mathrm{n} \text { ' in cell 's' in period ' } \mathrm{h} \text { ' is removed } \\ \mathrm{X}_{\mathrm{jtnsh}} & =1, \text { if part type 't' operation ' } \mathrm{j} \text { ' is carried out on machine type ' } \mathrm{n} \text { ' in cell 's' at } \\ & \text { duration ' } \mathrm{h} \text { ' } \\ & =0, \text { otherwise }\end{array}$

Q $\quad$ Part ' $t$ ' number allows their 'jth' operation to be done by a machine type ' $n$ ' incell 'c' during period 'h.'

$\mathrm{Y}_{\text {th }} \quad=1$, if $\mathrm{Q}_{\mathrm{th}}>0$;

0 , otherwise.

$\mathrm{C}_{\mathrm{th}} \quad$ The amount of demand for part ' $\mathrm{t}$ ' in duration ' $\mathrm{h}$ ' to be subcontracted.

$\mathrm{I}_{\mathrm{th}} \quad$ Inventory/back order-level part ' $\mathrm{t}$ ' at the end of the period ' $h$ '.

The negative value of $\mathrm{I}_{\mathrm{th}}$ shows the degree of shortage set back. 
The proposed model is required to satisfy the following requirements:

1. Concurrently defining unit groups with component families

2. Determining the best possible number of cells at each time interval.

3. The growing cycle shall determine the most suitable process plan for each component.

4. Identify machines in each era, by type requirement.

5. Determine machines in cells, by removing or increasing the number of machines between times.

6. Allowing different batch types for each component with material handling in inter / intracellular.

\subsection{Assumptions}

The model which was developed has the following assumptions:

1. Every type of component has a set of operations, and a selection of processes runs those known operations. The series of operations will start with number 1 .

2. Any given machine has known part type operations with a clearly defined processing time.

3. The efficiency and ability of the system are a known constant and the efficiency of any system is always constant at any output or planning time.

4. The cost of each machine is explicitly predefined as a variable. Using or running an optimally capacitated computer provides an operating cost that will be taken as the variable cost.

5. Machines with predefined costs are transferred from cell to cell.

6. Parts shall be processed in any batch between and within cells. Many outside a cell or intra-cell connected with the type of part have predefined costs and different sizes.

7. The adaptability of any machine for one or more operations does not entail an adjustment expense for the process in question.

8. Many machines will be able to perform a given operation but the processing time will vary.

9. Queues are undesirable in manufacturing.

\subsection{Model formulation}

The proposed model as follows:

$$
\begin{gathered}
\min \mathrm{Z}=\sum_{h=1}^{H} \sum_{n=1}^{N} \sum_{s=1}^{S} N_{n s h} \alpha_{n}+\sum_{h=1}^{H} \sum_{s=1}^{S} \sum_{t=1}^{T} \sum_{j=1}^{O_{t}} \sum_{n=1}^{N} B_{n} \cdot Q_{t h} . t_{j t h} . X_{j t n s h} \quad--1 \mathrm{a} \\
+1 / 2 \sum_{h=1}^{H} \sum_{t=1}^{T} \sum_{j=1}^{O_{t}-1} \sum_{s=1}^{S}\left[\frac{Q_{t h}}{B_{t}^{\text {int } r a}}\right] \cdot I^{\text {int } r} \times\left|\sum_{n=1}^{N} X_{(j+1) t n s h}-\sum_{n=1}^{N} X_{j t n s h}\right| \\
+1 / 2 \sum_{h=1}^{H} \sum_{t=1}^{T} \sum_{j=1}^{O_{t}-1} \sum_{s=1}^{S}\left[\frac{Q_{t h}}{B_{n}^{\text {int } r a}}\right] \times I^{\text {int } r a}\left(\sum_{n=1}^{N}\left|X_{(j+1) t n s h}-X_{j t n s h}\right|-\left|\sum_{n=1}^{N} X_{(j+1) t n s h}-\sum_{n=1}^{N} X_{j t s h}\right|\right) \\
+1 / 2 \sum_{h=1}^{H} \sum_{s=1}^{S} \sum_{n=1}^{N} \delta_{n}\left(K_{n s h}^{+}+K_{n s h}^{-}\right) \\
+\sum_{h=1}^{H} \sum_{t=1}^{T}\left(\eta_{\mathrm{t}} \mathrm{I}_{\mathrm{ht}}^{+}+\rho_{t} I_{h t}^{-}+\lambda_{t} \mathrm{C}_{\mathrm{th}}\right) \\
\mathrm{s.t.}
\end{gathered}
$$




$$
\begin{aligned}
& \sum_{s=1}^{S} \sum_{n=1}^{N} a_{j t n} X_{j t n c h}=y_{h t} \forall j, t, h \\
& \sum_{t=1}^{T} \sum_{j=1}^{O_{t}} Q_{t h} t_{j t n} X_{j t n s h} \leq T_{n} N_{n s h} \forall n, s, h \quad---3 \\
& \sum_{n=1}^{N} N_{n s h} \forall s, h \quad---4 \\
& \mathrm{~N}_{\mathrm{ns}(\mathrm{h}-1)}+\mathrm{K}_{\mathrm{nsh}}{ }^{+}-\mathrm{K}_{\mathrm{nsh}}{ }^{-}=\mathrm{N}_{\mathrm{nsh}} \forall \mathrm{n}, \mathrm{s}, \mathrm{h} \quad---5 \\
& \mathrm{I}_{\mathrm{th}}=\mathrm{I}_{\mathrm{t}(\mathrm{h}-1)}+\mathrm{Q}_{\mathrm{th}}+\mathrm{C}_{\mathrm{t}(\mathrm{h}-1)}-\mathrm{D}_{\text {th }} \quad \forall \mathrm{t}, \mathrm{h} \quad---6 \\
& \mathrm{I}_{\text {th }}{ }^{+} \leq \mathrm{I}_{\text {th, }}, \mathrm{I}_{\text {th }}{ }^{-} \geq-\mathrm{I}_{\text {th }} \forall \mathrm{t}, \mathrm{h} ; \mathrm{I}_{\mathrm{th}}=0 \forall \mathrm{t} \quad---7 \\
& \mathrm{Q}_{\text {th }} \leq \mathrm{M}^{\infty} \mathrm{y}_{\text {th }} \forall \mathrm{t} \text {,h } \\
& \mathrm{X}_{\mathrm{jtnsh}}, \mathrm{y}_{\mathrm{th}} \in\{0,1\}, \mathrm{K}_{\mathrm{nsh}}{ }^{+}, \mathrm{K}_{\mathrm{nsh}}{ }^{-}, \mathrm{N}_{\mathrm{nsh}}, \mathrm{Q}_{\mathrm{th}}, \mathrm{I}_{\mathrm{th}}{ }^{+}, \mathrm{I}_{\mathrm{th}}{ }^{-}, \mathrm{C}_{\mathrm{th}} \geq 0 \text { \& integer, }-\infty<\mathrm{I}_{\mathrm{th}}<\infty \text { \& integer --- } 9
\end{aligned}
$$

The objective feature of the Eq. Consists of the Eq.(1a)-(1d) built-in model(s). The Eq.(1a) is a gross sum of fixed and variable system costEq.(1b) represents the sum of intercellular/intracellular material handling costs. Eq.(1c) implies the cost of reconfiguration. Eq.(1d) is a combined amount of the preparation costs of production (Inventory holding, backlog, and subcontracting costs). Eq.(2) is that only one machine and one cell is allocated for each part-operation if at the time a portion of the part-demand is to be made. Eq.(3) ensures system capability is not surpassed, and the demand must be met. Eq.(4) ensures no violation of the maximum cell size. Eq.(5) is referred to as constraint on balance which ensures that as many machines as possible moving in during the existing process is equivalent to the number of running machines in the preceding duration plus the number of running machines, and less the number of running machines. Eq.(6) sets out the restriction on the stock balance of the cycles for each product phase at each time period. Eq.(8) Determine the degree of return/stock for each part category at each time period. Eq.(9) complements Eq.(2) to ensure that, where its operations are distributed in the first constraint set out in Eq.(2), a portion of the component demand can be generated at the given time. Eq. (1c), (6) and (7) have a relationship between the time horizons. Delete Eq. (1d) and let Eq. (7)-(9) relax. From a complexity perspective, the scale of the suggested model is directly relative to the number of processes, the sections, and the duration of the horizon planning. Consider model consists of ' $t$ ' part types, ' $n$ ' machine types, and ' $h$ ' periods where each part type is considered to have 'j' operation, and each operation is carried out on alternative 'L' machines. Additionally, presume that all types of parts across all times are subjected to a demand rate. Therefore each element category has $\mathrm{L}^{\mathrm{j}}$ process plans and there will be $\left[\mathrm{L}^{\mathrm{j}}\right]^{\mathrm{t}}$ process plans for each component sort at any given time. Therefore, $\mathrm{A} 1=\left(\left[\mathrm{L}^{\mathrm{j}}\right]^{\mathrm{t}}\right)^{\mathrm{h}}$ planning period variants for the allocation of part-operations to machines. A1 illustrates the solution space for the CMS model. To evaluate the size of the solution space associated with the mooted integrated model, momentarily ignore the restricted approach to subcontracting and assume that each type of component can either be produced or subcontracted. Thus each part form has $L^{j}+1$ process plans, and then $\mathrm{A} 2=\left(\left[\mathrm{L}^{\mathrm{j}}+1\right]^{\mathrm{t}}\right){ }^{\mathrm{h}}$. Likewise, let the quantity of stock / back-order be as complete. It implies that in certain h-1 preceding or subsequent periods complete demand for that component can also be contented at the given time. Consequently, each form of component has process plans $L^{j}+1+(h-1)=L^{j}+h$. In the simplistic case, the desired integrated model has combinations of $A 2=\left(\left[\mathrm{L}^{\mathrm{j}}+\mathrm{h}\right]^{\mathrm{t}}\right)^{\mathrm{h}}$ allocation; where $\mathrm{A}_{2}=\mathrm{A}_{1}+\mathrm{Q}$ and $\mathrm{Q}$ are a polynomial as $Q=\sum_{i=1}^{h \times t}\left(\begin{array}{l}h \times t \\ i\end{array}\right)\left(\begin{array}{l}j \\ L^{j}\end{array}\right)^{h \times t-i} h^{i}$

\section{Linearization:}

The planned show is a programming model of nonlinear numbers in view of the supreme terms in Eq-(1b) and a result of the choice factors in conditions with Eq-(1a),(1b), and (3). The linearization stage is executed in 2 phases. In the initial phase, total terms are changed in a direct frame as takes after: binaryvariablesg ${ }_{\mathrm{jtsh}}^{1}$ andg $_{\mathrm{jtsh}}^{2}$ areintroducedin Eq.(1b)and as follows:

$$
1 / 2 \sum_{h=1}^{H} \sum_{t=1}^{T} \sum_{j=1}^{O_{n}-1} \sum_{s=1}^{S}\left[\frac{Q_{t h}}{B_{t}^{\text {inter }}}\right] I^{\text {inter }} \cdot\left(g_{j t s h}^{1}+g_{j t s h}^{2}\right)---10
$$

In addition to the original model, the constraints are added: 


$$
g_{j t s h}^{1}-g_{j t s h}^{2}=\sum_{n=1}^{N} x_{(j+1) t n s h}-\sum_{n=1}^{N} x_{j t n s h}---11
$$

If there are two consecutive operations $\mathrm{j}, \mathrm{j}+1$ to part $\mathrm{t}$ is attributable to machines in identical cells, Eq-(11) right hand side is ' 0 ' and we have $-\mathrm{g}^{2}{ }_{\text {jtsh }}=0=>\mathrm{g}_{\mathrm{jtsh}}^{1}=\mathrm{g}_{\mathrm{j} \text { tsh }}^{2} \geq 0$. Eq-(1b) minimization enforces the $\mathrm{g}_{\mathrm{j} \text { tsh }}^{1}$ and $\mathrm{g}_{\mathrm{j} \text { tsh }}^{2}$ variables to be zero. Since these presume that two separate cells are allocated to operations $j+1$ of part $t$, the correct sense of Eq-(11) is either 1 or -1 .In this case, we have $\mathrm{g}_{\text {itsh }}^{1} \mathrm{~g}_{\text {jtsh }}^{2}=1$ and then $\mathrm{g}^{1}{ }_{\text {itsh }}=1$ and $\mathrm{g}_{\text {jtsh }}^{2}=0$ if the correct sense $=1$ is. In contrary cases, if the right side is $=-1$, we have $\mathrm{g}_{\text {jish }}=0$ and $\mathrm{g}_{\text {jtsh }}^{2}=1$, and therefore intercellular movement in Eq-(10) is countered. In the same way, the 2nd term of Eq-(1b) must be modified in linear form, binary variables $\mathrm{y}_{\mathrm{jtnsh}}^{1}$ and $\mathrm{y}_{\mathrm{j} \text { tnsh }}^{2}$ are presented and this is rewritten as:

$$
\sum_{h=1}^{H} \sum_{t=1}^{T} \sum_{j=1}^{O t-1} \sum_{s=1}^{S}\left[\frac{Q_{t h}}{B_{t}^{\text {int } r a}}\right] I^{\mathrm{int} r a}\left\{\sum_{n=1}^{N}\left(y_{j t n s h}^{1}+y_{j t n s h}^{2}\right)-\left(g_{j t s h}^{1}+g_{j t s h}^{2}\right)\right\} \quad--12
$$

In addition to the original model, the constraints areadded:

$\mathrm{y}_{\text {jtnsh }}^{1}-\mathrm{y}^{2}{ }_{\mathrm{jtnnh}}=\mathrm{X}_{(\mathrm{j}+1) \mathrm{tnsh}}-\mathrm{X}_{\mathrm{jtnsh}} \forall \mathrm{j}, \mathrm{t}, \mathrm{n}, \mathrm{s}, \mathrm{h} \quad---13$

Eq. (13) is found to be similar to Eq. (11). and Eq. (13) is rewritten as below:

$$
\begin{aligned}
& 1 / 2 \sum_{h=1}^{H} \sum_{t=1}^{T} \sum_{j=1}^{O t-1} \sum_{s=1}^{S}\left[\frac{\psi^{1}{ }_{j t s h}}{B_{t}^{\text {inter }}}\right] I^{\mathrm{inter}}---14 \\
& \Psi_{\mathrm{jtsh}}^{1} \geq \mathrm{Q}_{\mathrm{th}}-\mathrm{M}^{\infty}\left(1-\mathrm{g}_{\mathrm{jtsh}}^{1}-\mathrm{g}_{\mathrm{jthh}}^{2}\right) \forall \mathrm{j}, \mathrm{t}, \mathrm{s}, \mathrm{h} \\
& \Psi_{\mathrm{jtsh}}^{1} \leq \mathrm{Q}_{\mathrm{th}}+\mathrm{M}^{\infty}\left(1-\mathrm{g}_{\mathrm{jtsh}}^{1}-\mathrm{g}_{\mathrm{jtsh}}^{2}\right) \forall \mathrm{j}, \mathrm{t}, \mathrm{s}, \mathrm{h}---15
\end{aligned}
$$

Eq-(15) forces $\Psi^{1}{ }_{\mathrm{jtsh}}=\mathrm{Q}_{\mathrm{th}}$, if operation $\mathrm{j}$ or $\mathrm{j}+1$ is process in various cells or else $\Psi^{1}{ }_{\mathrm{jtph}}$ is zero. Similarly, Eq(12) to be in linear form by introducing $\Psi_{\text {jtsh }}^{2}$ (non-negative variable) is rewritten as Eq.(16).

$$
\begin{aligned}
& 1 / 2 \sum_{h=1}^{H} \sum_{t=1}^{T} \sum_{j=1}^{O_{t}-1} \sum_{s=1}^{S}\left[\frac{\psi 2_{j t s h}}{B_{t}^{\mathrm{int} r a}}\right] I^{\mathrm{int} r a}---16 \\
& \quad \text { where }, \Psi^{2}{ }_{\mathrm{jtsh}} \geq \mathrm{Q}_{\mathrm{th}}-\mathrm{M}^{\infty}\left\{1-\sum_{n=1}^{N}\left(y_{j t n s h}^{1}+y_{j t n s h}^{2}\right)+\left(g_{j t s h}^{1}+g_{j t s h}^{2}\right)\right\} \forall \mathrm{j}, \mathrm{t}, \mathrm{s}, \mathrm{h} \\
& \Psi_{\mathrm{jtsh}}^{2} \leq \mathrm{Q}_{\mathrm{th}}+\mathrm{M}^{\infty}\left\{1-\sum_{n=1}^{N}\left(y_{j t n s h}^{1}+y_{j t n s h}^{2}\right)+\left(g_{j t s h}^{1}+g_{j t s h}^{2}\right)\right\} \forall \mathrm{j}, \mathrm{t}, \mathrm{s}, \mathrm{h}---17
\end{aligned}
$$

Likewise,Eq-(17)forces $\Psi^{2}{ }_{\text {jtth }}=Q_{\text {th }}$, When j or j +1 is performed with 2 altered tackles. Otherwise, $\Psi^{2}{ }_{\text {jth }}$ is zero. Transforming $2^{\text {nd }}$ Eq. term (1a) and Eq. (3) is the non-negative term, in linear forms $\varphi_{j t n s h}$ is also superseded in the above terms by $\mathrm{Q}_{\mathrm{th}}$ and $x_{j t n s h}$. Therefore, the following requirement of constraints is an auxiliary to the original.

$$
\begin{aligned}
& \varphi_{j t n s h} \geq Q_{t h}-M^{\infty}\left(1-x_{j t n s h}\right) \forall j, t, n, s, h \\
& \varphi_{j t n s h} \leq Q_{t h}+M^{\infty}\left(1-x_{j t n s h}\right) \forall j, t, n, s, h \quad---18
\end{aligned}
$$

The finalmodelis,

$$
\operatorname{minZ}=\sum_{h=1}^{H} \sum_{n=1}^{N} \sum_{s=1}^{S} N_{n s h} \alpha_{n}+\sum_{h=1}^{H} \sum_{s=1}^{S} \sum_{t=1}^{T} \sum_{j=1}^{O_{t}} \sum_{n=1}^{N} B_{n} t_{j t n} \varphi_{j t n s h}+E q .(14)+E q .(16)+E q .(1 c)+E q .(1 d)--19
$$


Eq. (2) $\quad \sum_{t=1}^{T} \sum_{j=1}^{O_{p}} t_{j t n} \varphi_{j t n s h} \leq T_{n} N_{n s h} \forall n, s, h \mathrm{t}_{\mathrm{jtn}} \varphi_{\mathrm{jtnsh}} \leq \mathrm{T}_{\mathrm{n}} \mathrm{N}_{\mathrm{nsh}} \forall \mathrm{n}, \mathrm{s}, \mathrm{h}$

Eqs (4)-(9), (11), (13), (15), (17), (18)

$\mathrm{y}^{1}{ }_{\text {jtnsh }}, \mathrm{y}^{2}{ }_{\mathrm{jtnsh}}, \mathrm{Z}^{1}{ }_{\mathrm{jtsh}}, \mathrm{Z}_{\mathrm{jtsh}}^{2} \mathrm{C}\{0,1\}$;

$\Psi^{1}{ }_{\text {jtsh }}, \Psi^{2}{ }_{\text {jtsh }}, \varphi_{\mathrm{jtnsh}} \geq 0$ and integer.

\section{Optimal solution procedure}

The actual non-linear equation has been transformed into a linear form in the earlier section. This linear model is solved using MATLAB software by means of the matrix chain multiplication of dynamic programming algorithm. The model to corroborate the adoption of the proposed classic is implemented in this research work for the live case study for an automotive parts manufacturing industry in India. Fig.1 shows the concept flow diagram.

The general steps of dynamic programming are indicated as follows:

1. Determine the structural characteristics and the essence of the ideal solution.

2. Recursively defines the optimal solution.

3. Calculate and store the best sub-problem solutions by bottom-up manner.

4. Build the optimum solution for the initial problem, based on the data obtained in step 3 .

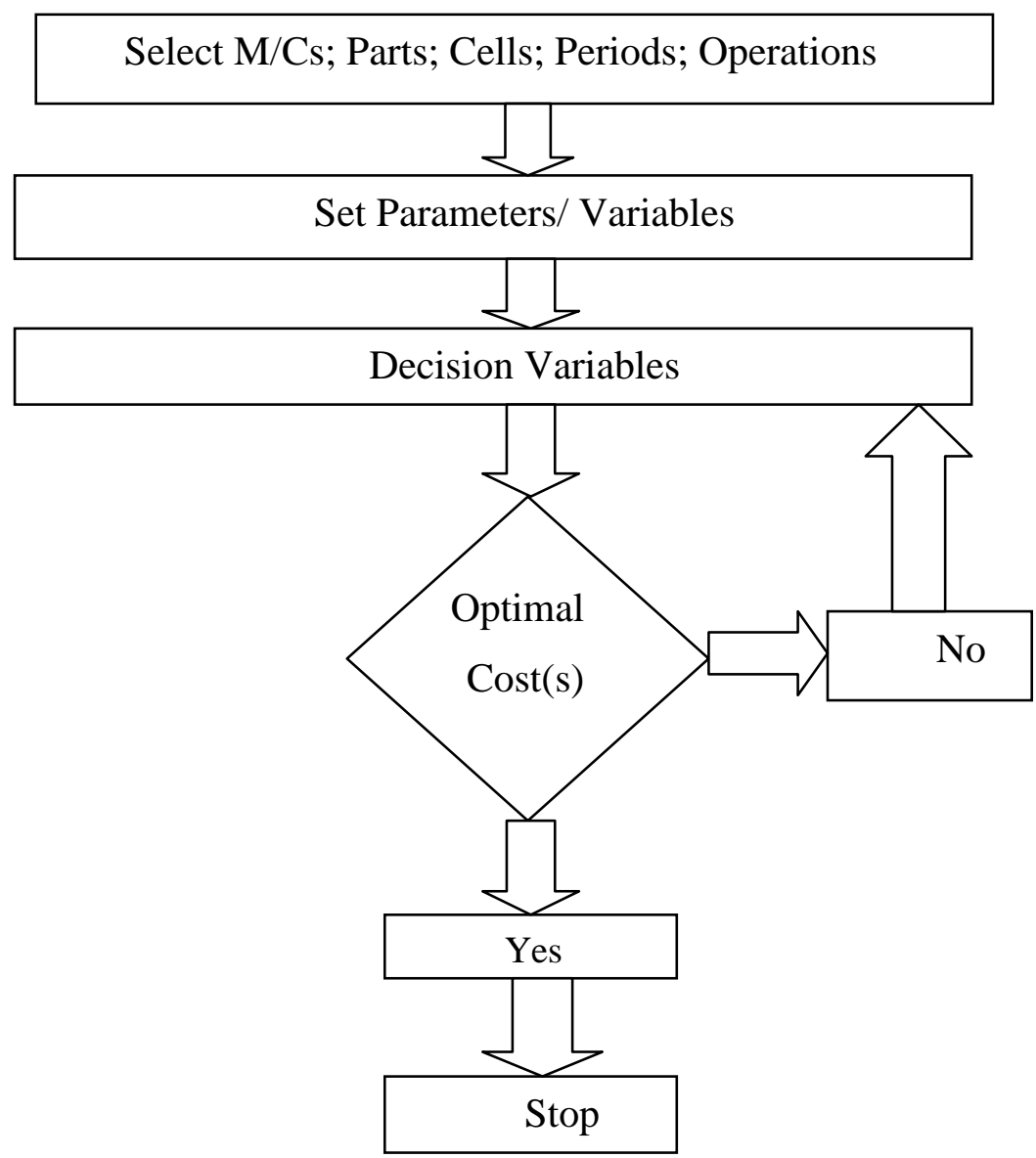

Fig. 1: Flowchart to case study

Now we are presenting an application of a created novel model to a case study real problem i.e. the live qualitative analysis consists of 7 forms of the part(s); 7 forms of the machine(s); 4 durations; Each form of part is acknowledged to at least 4 operations to conduct, respectively, Each function can be operated on 3 alternate machines in a complex production setting for multi-period manufacturing system due to rapid technology changes leading to advancements in automotive manufacturing units being updated to withstand and market survival. In this win-win scenario, mainly processes and costs (s) are critical issues to be optimized by the best efficient 
production planning of machines i.e. the latest equipment to produce different types of components as seven are taken over four time periods to perform four types of operations on alternative machines to be built as four cells for this Table 1 is made up of data parameters. and Table 2 reveals machine info i)capacity in hours, ii) fixed cost; iii) variable cost, and iv) machine rearrangement cost.

Table 1: Parameters Data

\begin{tabular}{|l|l|}
\hline Parameter & Value \\
\hline$D_{\mathrm{th}}$ & $\mathrm{u}(100,1000)$ \\
\hline $\mathrm{t}_{\mathrm{jtn}}$ & $\mathrm{u}(0,1)$ hour \\
\hline$\Sigma_{\mathrm{n}}$ jitn & $4 \forall \mathrm{j}, \mathrm{t}$ \\
\hline$\alpha_{\mathrm{n}}$ & Rs. $\mathrm{u}(950,3500)$ \\
\hline$\beta_{\mathrm{n}}$ & Rs. $\mathrm{u}(950,3500)$ \\
\hline$\delta_{\mathrm{n}}$ & Rs. $\mathrm{u}(150,300)$ \\
\hline $\mathrm{B}_{\mathrm{t}}$ Inter & $\mathrm{u}(100,500) \mathrm{units}$ \\
\hline $\mathrm{B}_{\mathrm{t}}$ Intra & $\beta_{\mathrm{t}}$ Inter $/ 5$ \\
\hline$\lambda_{\mathrm{t}}$ & Rs. $\mathrm{u}(0.10,0.50)$ \\
\hline$\eta_{\mathrm{t}}$ & Rs. $\mathrm{u}(0.10,0.50)$ \\
\hline$\rho_{\mathrm{t}}$ & Rs. $(0.10,0.20)$ \\
\hline $\mathrm{I}_{\mathrm{Ot}}$ & $\chi^{2}\left(0, \max \left\{\mathrm{D}_{\mathrm{th}}\right\}\right)$ \\
\hline
\end{tabular}

In the following table, batch sizes for inter and intra-cell, backorder costs, production costs, the quantity of demand, and production were presented at the start form in each duration for each component.

Table 2: Typical Case Data

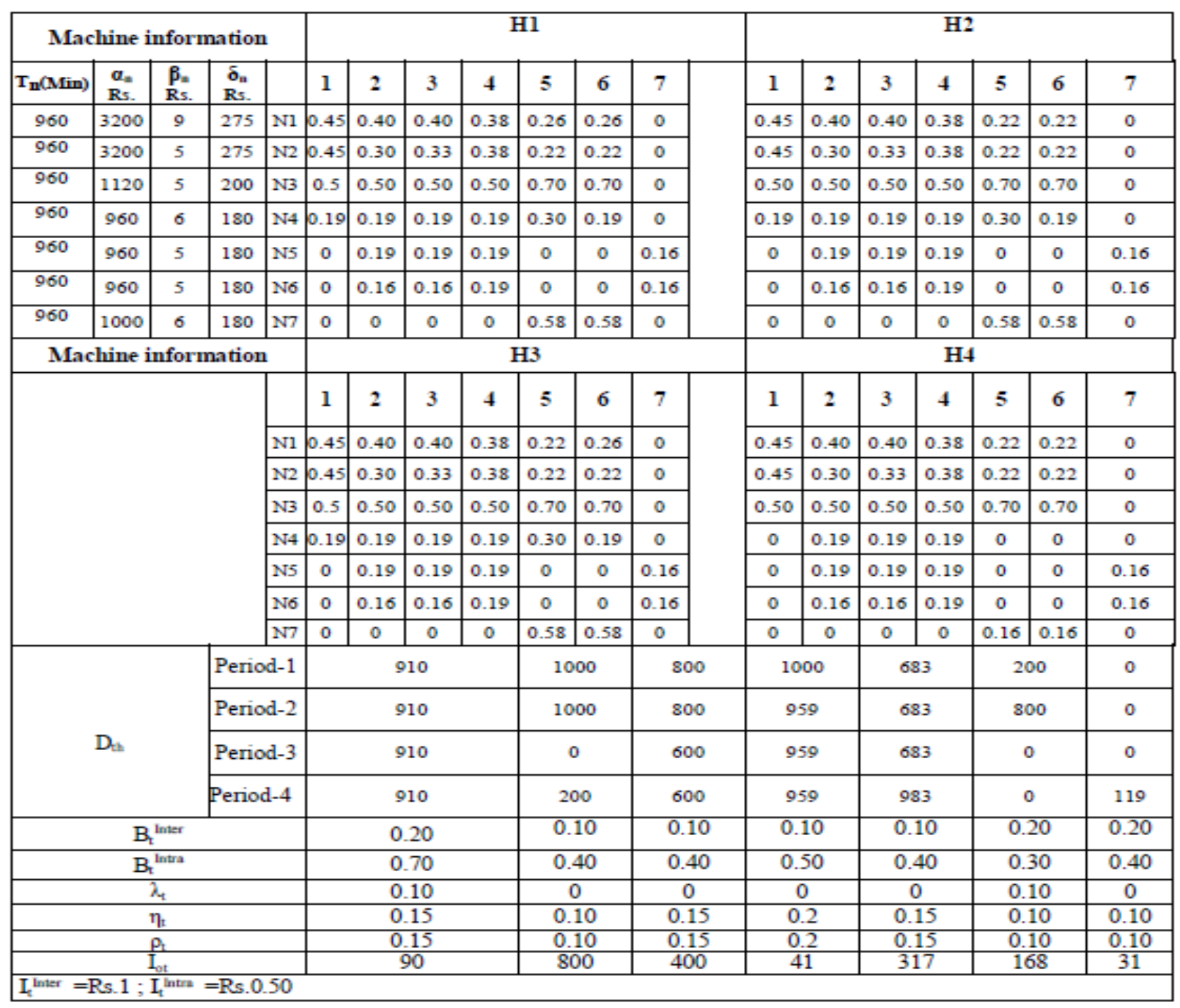


We considered that the automotive parts manufacturing industry is being manufactured for a case study with part(s) of a batch scale. Functional architectures in this industry have cost-time-process problems. Many of them are i) material cost to pass, ii) more work-in-progress, and iii) weak alignment to eliminate scraping and departmental rework. Conversion of the job shop design into CMS layout should eradicate problems described earlier. The conversion included comprehensive data collection to be tabulated in Table 2 which presents data for parts and machines operations. There are complete processes, cycle times, and alternative routings. Each form of a component has more than 4 separate operations. We considered that the automotive parts manufacturing industry is being manufactured for a case study with part(s) of a batch scale. Functional architectures in this industry have cost-time- problems. 4 alternate machines can handle any job at hand. Data for part types covers (i) batch size for intracellular movement and intercellular movement, (ii) intra/intercellular material handling costs per batch (iii) parts demand in four periods. The linear mathematical model proposed for the case study has 2401 outcome variable values for each cycle and a total of 9604 variables for four cycles. The function blends for the structured model under the main case with four cycles of uncertainty would be more in it 15748 input variables and 7301 decision variables.

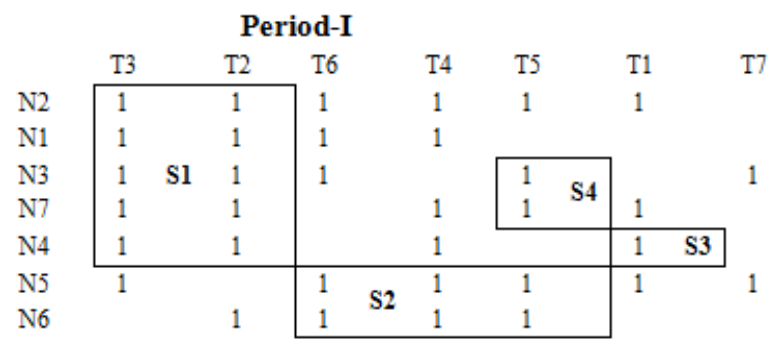

\begin{tabular}{|c|c|c|c|c|c|c|c|c|c|}
\hline \multicolumn{10}{|c|}{ Period-III } \\
\hline & \multicolumn{2}{|l|}{ T3 } & T4 & $\mathrm{T} 2$ & T6 & & T5 & & $\mathrm{T} 1$ \\
\hline N7 & 1 & & 1 & 1 & 1 & & 1 & & 1 \\
\hline $\mathrm{N} 2$ & 1 & & 1 & 1 & 1 & & 1 & & 1 \\
\hline N1 & 1 & Sl & 1 & 1 & 1 & & 1 & & \\
\hline N5 & 1 & & 1 & 1 & 1 & & & & \\
\hline N6 & 1 & & 1 & 1 & & & 1 & S3 & 1 \\
\hline N4 & 1 & & 1 & & 1 & S2 & 1 & & 1 \\
\hline N3 & 1 & S4 & 1 & 1 & & & & & 1 \\
\hline
\end{tabular}

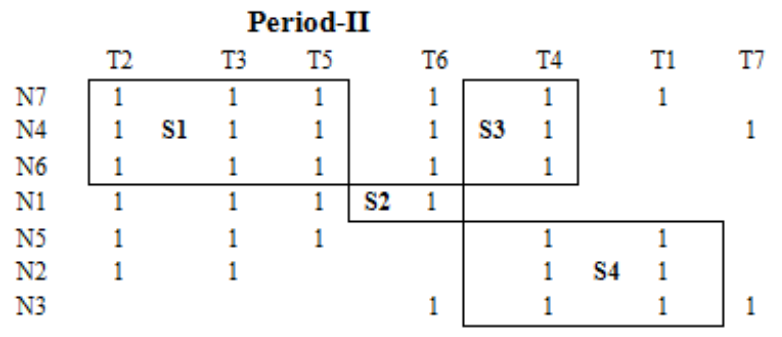

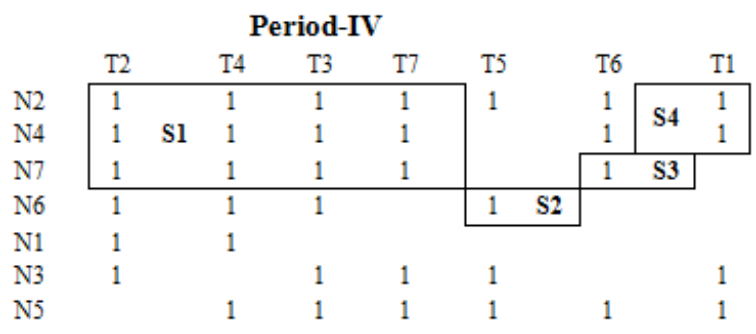

Fig. 2: Optimal Production Plan for Multi-Period Cell(s)

The cell configurations are shown in Fig. 2 as unit classes, part families, part process allocation, and system replication also summarizes the best solution obtained for the problem case, presenting the simultaneous unit cell formation and part families for all 4 times. For example, in cell 1 five different types of machines are allocated to period 1 and the part-operations are numbered within the cell. Five N2, N1, N3, N7, N4 machines are allocated to perform a number of Part 2 operations and these are all intercellular motions.

Table 3: Part -Machine cell indices for multi-period

\begin{tabular}{|c|l|l|l|l|}
\hline Period-No & Cell-1 & Cell-2 & Cell-3 & Cell-4 \\
\hline Period-1 & T3-T2=N2-N1-N3-N7-N4 & T6-T4-T5=N5-N6 & T1=N4 & T5=N3-N7 \\
\hline Period-2 & T2-T3-T5=N7-N4-N6 & T6=N1 & T4=N7-N4-N6 & T4-T1=N5-N2-N3 \\
\hline Period-3 & T3-T4-T2=N7-N2-N1-N5-N6 & T6=N4 & T5-T1=N6 & T3-T4-T2=N3 \\
\hline Period-4 & T2-T4-T3-T7=N2-N4-N7 & T5=N6 & T6=N7 & T1=N2-N4 \\
\hline
\end{tabular}

To carry out the leftover operations by adding a varied machine N6 in cell 2 for period 4 which allows the intercellular movement to part 2 i.e. with this type of cell formation we limited almost negligible number of both motions of the inter and intracellular wok component in a floor shop with which optimal solution cost for the model is presented in Fig.2. Table 3 represented the part-machine indices and in Table 4 the best ideal production schedule is presented. 
Table 4: Optimal Production Plan to the Case Study

\begin{tabular}{|c|c|c|c|c|c|c|c|c|c|c|c|c|c|c|}
\hline \multicolumn{8}{|c|}{$\mathrm{H}=1$} & \multicolumn{7}{|l|}{$\mathrm{H}=2$} \\
\hline & T1 & T2 & T3 & T4 & T5 & T6 & T7 & T1 & T2 & T3 & T4 & T5 & T6 & T7 \\
\hline $\mathbf{Q}_{\text {th }}$ & 1000 & 1000 & 1000 & 1000 & 1000 & 1200 & 300 & 1000 & 1000 & 1000 & 1000 & 1000 & 1200 & 300 \\
\hline $\mathrm{C}_{\mathrm{th}}$ & 0 & 0 & 0 & 0 & 0 & 0 & 0 & 0 & 0 & 0 & 0 & 0 & 2388 & 0 \\
\hline $\mathbf{I}_{\mathrm{th}}$ & 90 & 0 & 200 & 41 & 317 & 168 & 31 & 90 & 0 & 200 & 41 & 317 & 168 & 31 \\
\hline $\mathbf{D}_{\text {th }}$ & 910 & 1000 & 800 & 959 & 683 & 200 & 0 & 910 & 1000 & 800 & 959 & 683 & 200 & 0 \\
\hline \multicolumn{8}{|c|}{$\mathbf{H}=\mathbf{3}$} & \multicolumn{7}{|l|}{$\mathrm{H}=4$} \\
\hline & T1 & T2 & T3 & T4 & T5 & T6 & T7 & T1 & T2 & T3 & T4 & T5 & T6 & T7 \\
\hline $\mathbf{Q}_{\mathrm{th}}$ & 1000 & 1000 & 1000 & 1000 & 1000 & 1200 & 300 & 1000 & 1000 & 1000 & 1000 & 1000 & 1200 & 300 \\
\hline $\mathrm{C}_{\mathrm{th}}$ & 0 & 0 & 0 & 0 & 0 & 0 & 0 & 960 & 0 & 0 & 0 & 0 & 0 & 0 \\
\hline$I_{\text {th }}$ & 90 & $1000^{*}$ & $200^{*}$ & 41 & 317 & $1200^{*}$ & 31 & 90 & 800 & 400 & 41 & 17 & $\begin{array}{l}168 \\
\end{array}$ & 31 \\
\hline$D_{\text {th }}$ & 910 & 0 & 600 & 959 & 683 & 0 & 0 & 910 & 200 & 600 & 959 & 983 & 0 & 119 \\
\hline
\end{tabular}

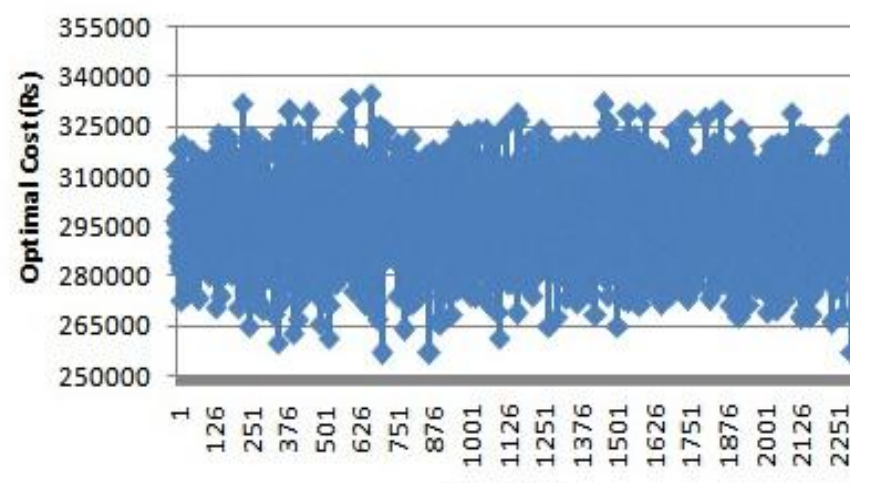

Optimal Cost for Period - I

No. of Expts
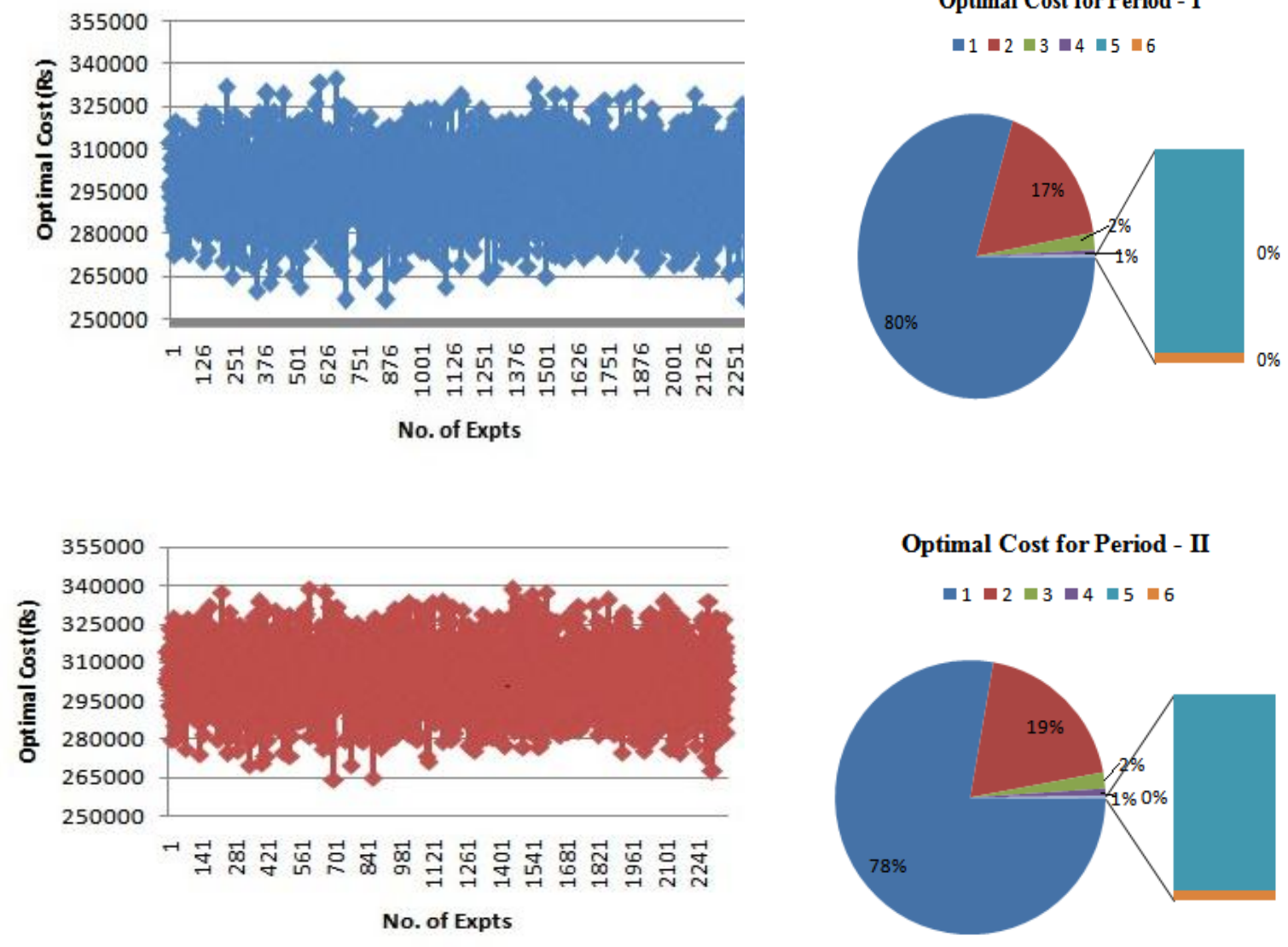

Optimal Cost for Period - II

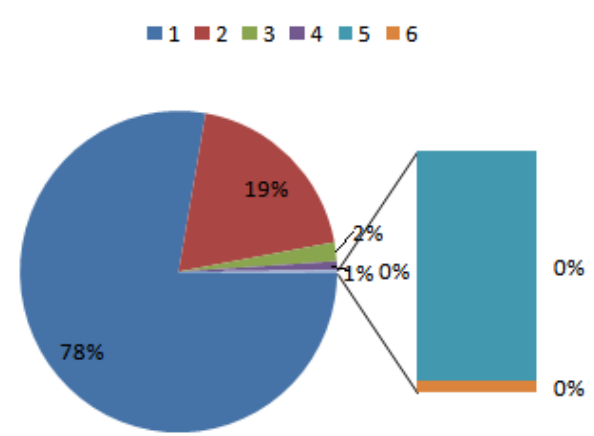



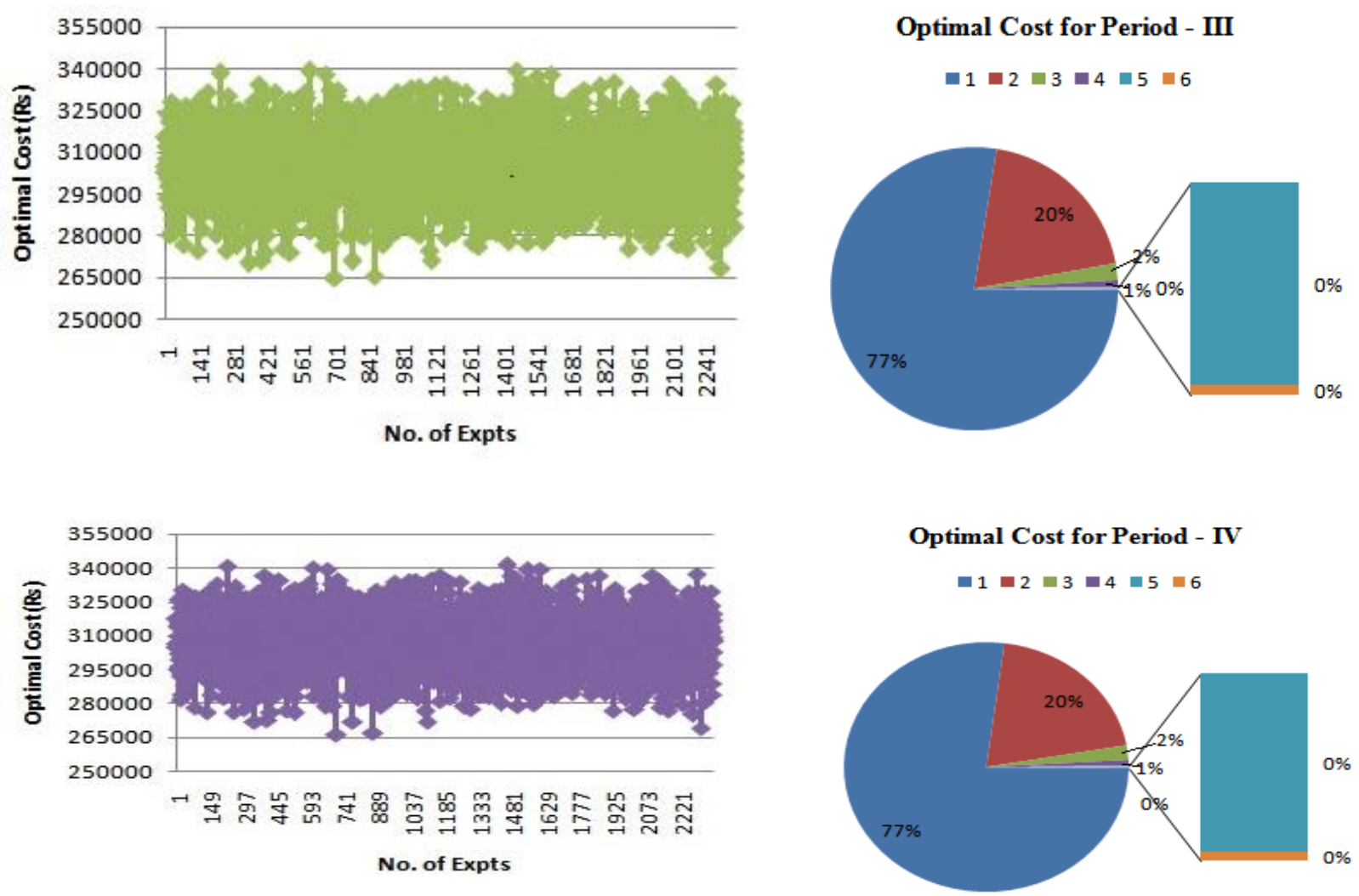

Fig. 3: Pie chart Representation of Optimal Cost(s) to the case study

Four- cell design is where four cells are constructed for each time and the optimal cost was represented in Table-5. For a multi-period case study, the optimum cost, i.e. a mixture of costs associated with the manufacturing method was described as a pie chart in Fig.3 and as a graph in Fig.4.

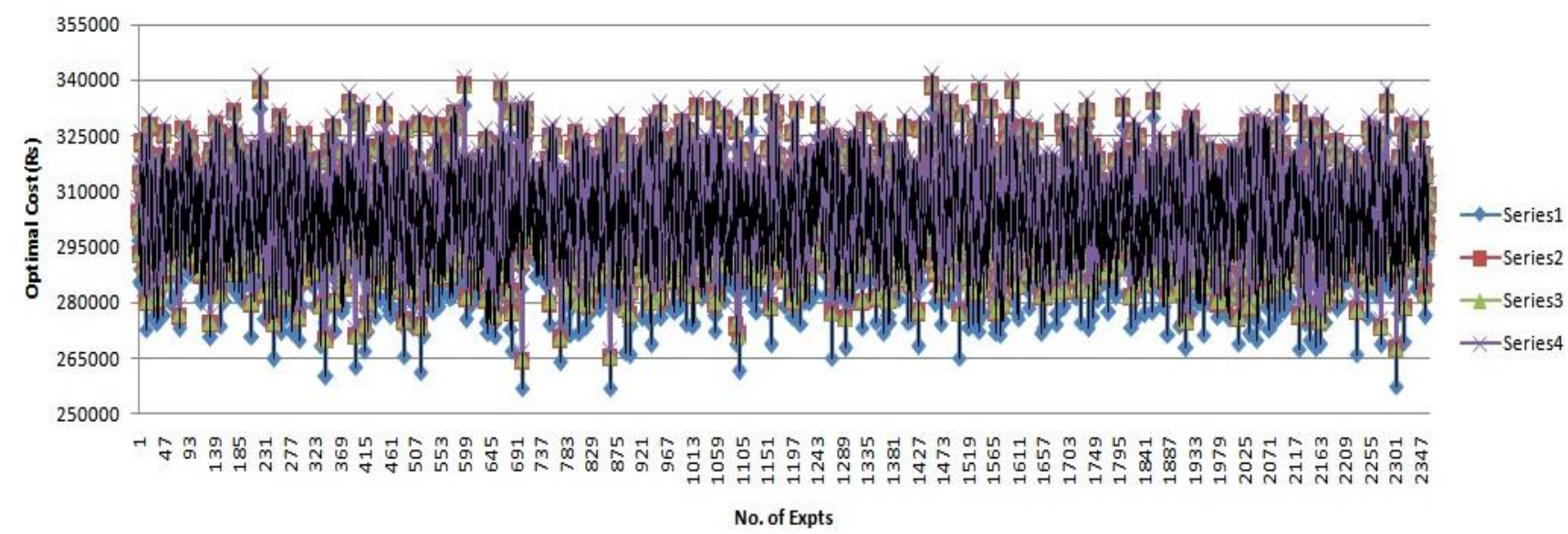

Fig. 4: Graphical representation of Optimal Cost(s) to the case study 
The optimal cell design of the multi-period value comparison of the model is presented in Fig.5 and Table-5.

\section{Optimal Solution}

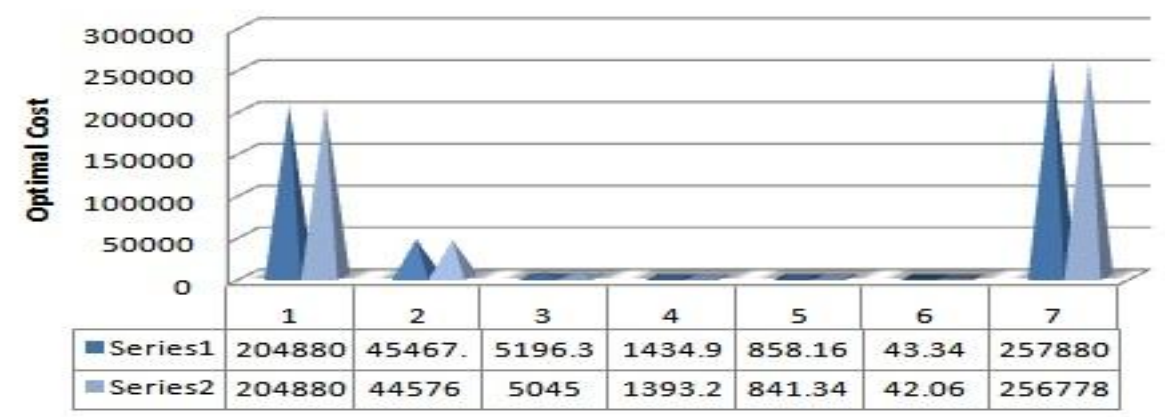

Fig.5: Optimal System solution in Rs.

Table 5: BestObtained Solution for the Case in Rs

\begin{tabular}{|r|c|c|c|c|c|c|c|}
\hline & $\begin{array}{c}\mathrm{M} / \mathrm{c} \\
\text { Constant } \\
\text { cost }\end{array}$ & $\begin{array}{c}\mathrm{M} / \mathrm{c} \\
\text { Variable } \\
\text { cost }\end{array}$ & $\begin{array}{c}\text { Reconfiguration } \\
\text { cost }\end{array}$ & $\begin{array}{c}\text { Inventory } \\
\text { cost }\end{array}$ & $\begin{array}{c}\text { Intercell } \\
\text { movement } \\
\text { cost }\end{array}$ & $\begin{array}{c}\text { Intracell } \\
\text { movement } \\
\text { cost }\end{array}$ & $\begin{array}{c}\text { Optimal } \\
\text { Cost }\end{array}$ \\
\hline Actual & 204880 & 45467.52 & 5196.35 & 1434.99 & 858.16 & 43.34 & 257880.36 \\
\hline Optimal \\
DPMCMA
\end{tabular}

\section{Conclusions}

A novel integrated mathematical model of multi-objective function to multi-criteria decision-making analysis by incorporating the big data analytics with green supply chain management to bridge the gap in demand. The proposed novel model has been implemented to a case study in the manufacturing industry for an automobile part manufacturing industry in India and the computational results illustrates that the algorithm proposed is effective.

\section{References}

Rejikumar, G.; Raja, V.; Arunprasad, P.; Jinil, P.; Sreeraj, K.M.2019. Industry 4.0: Key findings and analysis from the literature arena. Benchmarking Int. J. vol. 26, pp.2514-2542.

Stock, T.; Seliger, G.2016, Opportunities of sustainable manufacturing in Industry 4.0. Procedia CIRP, vol. 40,pp. 536-541.

Zeb, A., Khan, M., Khan, N. et al. 2016. Hybridization of simulated annealing with genetic algorithm for cell formation problem. Int J Adv Manuf Technol 86, 2243-2254.

https://doi.org/10.1007/s00170-015-8288-3

Ghosh, T., Doloi, B. \& Dan, P.K. 2016. Applying soft-computing techniques in solving dynamic multi-objective layout problems in cellular manufacturing system. Int J Adv Manuf Technol 86,

237-257. https://doi.org/10.1007/s00170-015-8070-6.

Soolaki,M.,Arkat,J. 2018. Incorporating dynamic cellular manufacturing into strategic supply chain design. Int J Adv Manuf Technol 95, 2429-2447. https://doi.org/10.1007/s00170-017-1346-2.

Wemmerlov.U.,and J.Johnson.D.1997.Cellular Manufacturing at 46 User Plants: Implementation Experiences and Performance Improvements. International Journal of Production Research 35, pp.29-49.

Chen.M.,\&Cao.D. 2004. Coordinating Production Planning in Cellular Manufacturing Environment using Tabu Search. Computers and Industrial engineering 46, pp. 571-588.

Rheault.M., Abdulnour.G and Drolet.J. 1995. Physically Reconfigurable Virtual Cells: A Dynamic Model for a Highly Dynamic Environment. Computers and Industrial Engineering 29 (4), pp.221-225.

Venkatadri, U., Elaskari, S.M. \& Kurdi, R. 2017. A multi-commodity network flow-based formulation for the multi-period cell formation problem. Int J Adv Manuf Technol 91, 175-187. https://doi.org/10.1007/s00170016-9673-2. 
Barenji, A.V., Barenji, R.V., Roudi, D. et al. 2017. A dynamic multi-agent-based scheduling approach for SMEs. Int J Adv Manuf Technol 89, 3123-3137. https://doi.org/10.1007/s00170-016-9299-4.

Hasan, S.M., Baqai, A.A., Butt, S.U. et al. 2018. Product family formation based on complexity for assembly systems. Int J Adv Manuf Technol 95, 569-585. https://doi.org/10.1007/s00170-017-1174-4.

Ashraf, M., Hasan, F. 2018. Configuration selection for a reconfigurable manufacturing flow line involving part production with operation constraints. Int J Adv Manuf Technol 98, 2137-2156. https://doi.org/10.1007/s00170-018-2361-7.

Asghar,E.,Zaman,U.K.,Baqai,A.A.et al.2018. Optimum machine capabilities for reconfigurable manufacturing systems. Int J Adv Manuf Techno, Volume 95, Issue 9-12, pp.4397-4417,

https://doi.org/10.1007/s00170-017-1560-y.

Harhalakis.G, Proth.J and Nagi.R. 1990. An Efficient Heuristic in Manufacturing Cell Formation for Group Technology Applications. International Journal of Production Research 28 (1), pp. 185-198.

Vakharia A, \& Kaku.B. 1993. Redesigning a Cellular Manufacturing System to Handle Long-term Demand Changes: A Methodology and Investigation. Decision Sciences 24 (5), pp. 84- 97.

Song.S and Hitomi.K. 1996. Integrating the Production Planning and Cellular Layout for Flexible Cellular Manufacturing. Production Planning and Control 7 (6), pp. 585-593.

Drolet.J, M.Rheault and G.Abdulnour. 1996. The Cellular Manufacturing Evolution. Computers and Industrial Engineering 31 (1), pp. 139-142.

Marcoux Y., Drolet.J, and Abdulnour. G. (1997). Studying the Performance of a Dynamic Cellular Manufacturing System. Computers and Industrial Engineering 31 (1-2), pp. 239- 242.

Askin.R, Vakharia.A, and H.Selim. 1997. A Methodology for Designing Flexible Cellular Manufacturing Systems, IIE Transactions 29 (7), pp. 599-610.

Wilhelm.W, D.Chang and Chiou.C. 1998. Integrating Design and Planning Considerations in Cellular Manufacturing. Annals of Operations Research 77 (1), pp. 97-107.

Chen. M. 1998. A Mathematical Programming Model for System Reconfiguration in a Dynamic Cellular Manufacturing Environment. Annals of Operations Research 77 (1), pp. 109- 128.

Taboun M.S., Ulger.T, N.Merchawi.S. 1998. Part Family and Machine Cell Formation in Multi-period Planning Horizons of Cellular Manufacturing Systems. Production Planning and Control 9(6), pp.561-571.

Wicks E.M.and J.Reasor.R. 1999. Designing Cellular Manufacturing Systems with Dynamic Part Populations. IIE Transactions 31, pp.11-20.

Arzi Y., Masin.M and Bukchin.J. 2001. An Efficiency Frontier Approach for the Design of Cellular Manufacturing Systems in a Lumpy Demand Environment. European Journal of Operations Research 134, pp. 346-364.

Balakrishnan.J. and H.Cheng.C. 2005. Dynamic Cellular Manufacturing under Multi-Period Planning Horizons. Journal of Manufacturing Technology Management 16 (5), pp. 516-530.

Safaei.N,F.Sassani,R.Tavakkoli-Moghaddam \& M.Saidi-Mehrabad. 2008. A Fuzzy Programming Approach for a Cell Formation Problem with Dynamic and Uncertain Conditions, Fuzzy Sets and Systems 159, pp. 215-236.

Aydin, R., Kwong, C.K., Geda, M.W. et al. 2018.Determining the optimal quantity and quality levels of used product returns for remanufacturing under multi-period and uncertain quality of returns. Int $\mathrm{J}$ Adv Manuf Technol 94, 4401-4414. https://doi.org/10.1007/s00170-017-1141-0.

JeonG \& R.Leep.H. 2006. Forming Part Families by using Genetic Algorithm and Designing Machine Cells under Demand Changes. Computers and Operations Research 33 (1), pp. 263-283.

Defersha.M.F. \& M.Chen. 2006. Machine Cell Formation using a Mathematical Model and A Genetic Algorithm based Heuristic. International Journal of Production Research 44 (12), pp. 2421-2444.

Defersha.M.F \& Chen.M. 2008. A Linear Programming Embedded Genetic Algorithm for an Integrated Cell Formation and Lot Sizing Considering Product Quality. European Journal of Operations Research 187 (1), pp. 46-69.

Schaller.J, (2007). Designing and Redesigning Cellular Manufacturing Systems to Handle Demand Changes. Computers and Industrial Engineering 53, pp. 478-490.

Pillai.M.V\&Subbarao.K. 2007. A Robust Cellular Manufacturing System Design For Dynamic Part Population using a Genetic Algorithm. International Journal of Production Research,pp.1-20.

Paydar, Mohammad Mahdi \& Saidi-Mehrabad, Mohammad. 2017. A hybrid genetic algorithm for dynamic virtual cellular manufacturing with supplier selection. The International Journal of Advanced Manufacturing Technology. 92. 1-17. 10.1007/s00170-017-0370-6.

Bruno, G., Antonelli, D. 2018. Dynamic task classification and assignment for the management of human-robot collaborative teams in work cells. Int J Adv Manuf Technol 98, 2415-2427. https://doi.org/10.1007/s00170018-2400-4.

Far, Mohammad \& Haleh, Hassan \& Saghaei, Abbas. 2019. A fuzzy bi-objective flexible cell scheduling optimization model under green and energy-efficient strategy using Pareto-based algorithms: SATPSPGA, 
SANRGA, and NSGA-II. The International Journal of Advanced Manufacturing Technology. 105. 10.1007/s00170-019-03797-w.

Huang,C.,Cheng,K.\&Holt,A.2007.An integrated manufacturing network management framework by using mobile agent. Int J Adv Manuf Technol 32, 822-833.https://doi.org/10.1007/s00170-005-0378-1.

\section{Author(s) Biography:}

Mr.Ponugupati Narendra Mohan is a research scholar in the Department of Mechanical Engineering, Andhra University, India. He received his M.Tech degree from Acharya Nagarjuna University, India in 2007, and B.Tech degree from JNTU, India in 2004. Present working as Assistant Professor in Department of Mechanical Engineering, Acharya Nagarjuna University, India from 2012 to till date. Before he joined Acharya Nagarjuna University in 2012, he was an Assistant professor in Department of Mechanical Engineering at SCREC from 2007 to 2012. Present research interests include manufacturing system and optimization.

Dr.Chalamalasetti Srinivasa Rao is a professor in the Department of Mechanical Engineering, Andhra University, India from 2006 to till date. He received his B.E degree from Acharya Nagarjuna University, India in 1988; M.Tech degree from Maulana Azad National Institute of Technology, India in 1991; and Ph.D. degree in mechanical engineering from Andhra University, India in 2004. Before he joined Andhra University in 2006, he was an Assistant Professor and Associate Professor at the Department of Mechanical Engineering of GITAMS, India from 1992 to 2006 . His current research interests are in the areas of advanced design and manufacturing. He has published over 196 research papers. 